\title{
Contextualising English generalist day centres for older people: operational characteristics and typical days. Findings from case study research
}

Katharine Orellana ( $\nabla$ katharine.orellana@kcl.ac.uk)

King's College London https://orcid.org/0000-0002-1315-3706

Jill Manthorpe

King's College London https://orcid.org/0000-0001-9006-1410

Anthea Tinker

King's College London https://orcid.org/0000-0002-0305-7198

\section{Research Article}

Keywords: day centre, day care, older people, community care, context, case study

Posted Date: December 17th, 2021

DOI: https://doi.org/10.21203/rs.3.rs-1028191/v2

License: () (i) This work is licensed under a Creative Commons Attribution 4.0 International License. Read Full License 


\section{Abstract}

Reports of Covid-19 pandemic related day centre closures impacting negatively on their attenders and family carers have fuelled a resurgence of interest in day centres, a common, but often 'invisible', preventive service. The absence of detailed descriptions of these services from the literature limits the evidence base since outcomes data without context are less meaningful.

This descriptive article aims to further understanding of these diverse and multi-faceted settings for potential collaborators and social care and health professionals, particularly in the context of rising social prescribing initiatives in England with their focus on linking older people to asset-based community resources.

Using data from documentation provided by managers of four purposively selected English day centres for older people, interviews with 23 centre managers, staff and volunteers, and notes made during 56 full-day visits, this article presents a rich, contemporary, non-interpretative, pre-Covid pandemic picture of four purposively selected English day centres for older people.

This baseline data will support conversations concerning optimisation of such services in the post-pandemic recovery period and beyond: how buildings may be regarded as valuable community assets with potential, and how other parts of the health and care system may better interact with day services to improve older people's, carers' and others' health and wellbeing, and to benefit of staff working elsewhere in health and care.

\section{Introduction}

A resurgence of interest in English older people's day centres is evident. Day centre closures during the 2020 Covid-19 pandemic, due to restrictions being placed on numbers of people allowed to gather, are reported to have impacted negatively on many attenders and family carers (Giebel et al., 2020; Tuijt et al., 2021). Previously, English national media had covered the potential negative health, wellbeing and financial consequences of day centre closures primarily as a result of local government funding cuts (Green, 2018; Roberton, 2018). Following a dearth of day centre research in England for several years, positive experiences and outcomes for day centre users, carers, their staff and volunteers have recently been reported in the United Kingdom (UK) (Hagan \& Manktelow, 2021; Lunt, Shiels, et al., 2021; BLINDED 2018; BLINDED 2020a, 2021a, 2021b), and a study of collective day services is currently (2021-23) being undertaken. [i]

This article describes and discusses the characteristics of four English day centres for older people. Such centres have been an integral part of social/community care since the middle of the last century (Hagan \& Manktelow, 2021; Tester, 1989; Thane, 2009; Tucker et al., 2005) but began to decline in numbers alongside the introduction of the policy of 'personalisation' (choice and control) (Needham, 2011), combined with public funding constraints and substantial cuts to day care provision (Ismail et al., 2014).

Day centres are diverse and complex building-based services that provide care/health-related services/activities specifically for older people who are disabled/in need, which people can attend for a whole day or part of a day. They may be owned by different provider types, operate in different building types, and may differ in size, target clientele and funding. They offer a variety of programmes (interventions) and the opportunity to socialise. They may be known as their local name (e.g. Tulip Centre) or as day care centres, day clubs/care/services, senior/multipurpose centres (BLINDED 2020b). Additional complicating elements of diversity contribute to uncertainty around the day centre intervention, for instance number of days attended, variability of individual experiences, and inherently different services provided where a person-centred approach is taken (Fields et al., 2014). English day centres are unregulated and the absence of a national representative body means accurate details of their provision are unavailable. Their diversity, together with being a service described by its location, instead of its aims, makes day centres difficult to research or evaluate (Fields et al., 2014), perpetuating the under-developed evidence base for social care preventive services (Allen \& Miller, 2013). This is problematic as evidence-based commissioning is encouraged (Local Government Association, 2015; NHS England et al., 2014).

Rich contextual data are often missing from research or systematic reviews (Wye et al., 2015). This absence of detailed descriptions of day centres and their aims may lead to assumptions of homogeneity and hamper a full understanding of this complex service and any outcomes resulting from its use - for attenders, carers, staff or volunteers - to be meaningfully gained. Manthorpe and Moriarty $(2013,2014)$ argued that having better data about day centres is important for those funding services or purchasing them on behalf of individuals. Details also would provide baseline information about what potential collaborating organisations might offer each other, given that local partnership working is encouraged (HM Government, 2014). These points are particularly pertinent as day centres have been subject to criticism for being unimaginative and institutionalising (see Hagan \& Manktelow, 2021; Needham, 2011; BLINDED 2020b). It is also possible that day services' broader potential has been obscured by cumulative effects of various (e.g. financial) challenges or inclination towards individual support or alternative daytime activities, such as those delivered by a small number of micro-enterprises (Reddington \& Fitzsimons, 2013) or green care (Finnanger-Garshol et al., 2021). This lack of knowledge and assumptions about day centres, particularly by those in a position of influence such as over referrals, extends even to palliative day care services which are also heterogeneous but unknown to many health care professionals (Hasson et al., 2021).

Four day centre case studies, now historical due to changed service structures, ethos and provision, are of note for their in-depth reporting of the setting itself and their contrast with contemporary contexts. Both Hazan's (1980) anthropological study of the concept of time in one English day centre for older Jewish people and Smith and Cantley's (1985) pluralistic evaluation of a new, English NHS psychogeriatric day hospital dedicate a chapter to describing the settings. Tester's (1989) study of day care services and facilities in England and Wales dedicated part of one chapter to seven very brief case studies of different types of centre, including two day hospitals. Gubrium's study (1986) in the United States was set in a dementia centre. 
Recent reviews of English language day centre literature have recommended research on day centres' characteristics to better contextualise their outcomes (Ellen et al., 2017; Lunt et al., 2018; Lunt, Dowrick, et al., 2021; BLINDED 2020b). Literature not included in these reviews devotes little space to contextual descriptions while reporting experiences, outcomes, centres' acceptability as a short break/respite, attender characteristics, access routes, programming, person-centred-ness, potential to support hospital discharge planning and post-hospital care, evaluation and planning (Hagan \& Manktelow, 2021; Leong et al., 2020; Liao \& DeLiema, 2021; Lunt, 2018; Naruse, Kitano, et al., 2020; Naruse, Tuckett, et al., 2020; O’ Shea et al., 2019; BLINDED 2020a, 2021a; Rokstad et al., 2019; Ruggiano et al., 2018; Thompson \& Fletcher, 2019). Most (short) descriptions of day centres and their activities concern day centres outside England, with added complications that some of these may also offer clinical services: Northern Ireland (Hagan \& Manktelow, 2021), US (Hostetler, 2011; Salari et al., 2006), Israel (lecovich \& Biderman, 2012), Norway (Boen et al., 2010; Lund \& Englesrud, 2008), Japan (Kuzuya et al., 2006), Canada (Wittich et al., 2014) and Taiwan (Liou \& Jarrott, 2018; 2013).

Apart from the study discussed in this present article, the most detailed contemporary data about English day centres for older people with multiple long-term conditions are reported by Lunt's (2018) doctoral thesis. Contextual data (funding, charges, places available, transport, opening times, activities, target/current attenders, access, referrals, staffing) are heavily summarised and blended across day centres for older people, people with dementia or learning disabilities as the study's purpose was to analyse impact by staffing model (Blended - staff and volunteers; Voluntary - run entirely by volunteers; and Paid - staffed by paid workers).

Finally, the NHS Long-Term Plan (NHS, 2019) details plans for increasing numbers of social prescribing link workers (community navigators) often based in NHS primary care networks. These workers make 'social prescriptions', referrals to or actual assistance with connecting people with social, emotional or practical needs to non-medical interventions (e.g. local groups, support services, community activity, volunteering) with a goal of improving their outcomes (NHS England, 2020). Outcomes include individual health and wellbeing improvements, and reduced use of primary and secondary healthcare (Polley et al., 2019). Although an enactment of personalised care and support with demonstrated potential to economically benefit the NHS, stakeholder buy-in is key (Fixsen et al., 2020).

Both in England and in countries where day centres are integrated into health and care systems, little is known about social care and health professionals' perceptions of day centres, particularly those commonly in contact with older people in need of care and support (e.g. family doctors, nurses, social workers, occupational therapists, social prescribers) (BLINDED 2020b). Referral, commissioning or funding decisions may be influenced by individual knowledge and pre-held assumptions about specific service types, perhaps resulting from professional background. Given English local authorities' role in shaping the care market (HM Government, 2014), increased social prescribing plans, and the efforts to build back better services following the Covid-19 pandemic, there is a need to highlght the evidence for day centres along several dimensions.

In summary, the homogeneity characterising some social care services - such as home care which typically involves one or two care workers visiting a person at home to undertake washing, (un)dressing, toileting assistance or incontinence pad changing, support with eating and drinking, which may include simple meal preparation, and mobilisation support - is not found among day centres for older people. Researchers are expected to report settings in which interventions take place and details of interventions under investigation yet day centre scholars reviewing their subject literature have raised the matter of scant data in this regard. Primary health initiatives relevant to day centres are underway in England. Therefore, the lack of detailed information about day centres and what happens at them is an ontological dilemma that this article aims to address.

\section{Aim of this article}

This article provides rich descriptions of the four English day centres for older people that participated in a pre-pandemic mixed methods study (BLINDED 2018), thus aiming to further understandings of this face-to-face, out-of-home care setting.

[i] Reimagining collective forms of day care provision for older people https://www.sscr.nihr.ac.uk/projects/p164/

\section{Methods}

This article draws on findings of a doctoral study of 'generalist' day centres[i] that used mixed methods within a case study approach to paint an in-depth and contemporary picture of four English day centres for older people, in the environment of 2014-2017, by investigating what they offered, their use, relationships with local health and care services, and professional perceptions (BLINDED 2018). The wider study gathered the perspectives of 69 stakeholders (local authority referrers and purchasers, day centre providers/managers/staff/volunteers, attenders and family carers) and operational data.

Case studies capture complexity of a contemporary phenomenon in its real-life context by using multiple sources of evidence (Stake, 1995; Yin, 2014). Generalisability is enhanced by strategically selecting cases (see Flyvbjerg, 2016; Hyett et al., 2014); generalisability, however, is less crucial than the use made of the case studies (Ruddin, 2016).

\section{Sample and recruitment}

Using maximum variation non-probability sampling (Creswell, 2013), four day centres in different local authority areas were recruited against a matrix of characteristics (provider, building designation, admission criteria, attender numbers, target users) in areas with different population characteristics, deprivation levels and local political administrations. Time and funding constraints meant centres were recruited from South-East England.

Centres were identified by consulting older people's service directories, local authority websites, web pages of known providers and by using internet search engines and mapped onto the typology matrix. A selection of centres was contacted, by telephone and email, inviting managers to discuss the study in person. Subsequent centre visits enabled further evaluation of day centres' suitability prior to recruitment. Local authorities were approached directly about in-house 
day centres. Both participating voluntary sector day centres were recruited via the organisational manager, one of whom also managed the day centre, who consented on their behalf; one also required a committee's approval. Approval from the housing association day centre manager's manager and a local authority commissioner was needed.

\section{Data collection and analysis}

Data presented here, collected between October 2015 and December 2016, derive from documentation provided by managers (e.g. newsletters, activity programmes), single, qualitative interviews with day centre/provider managers $(n=6)$, frontline staff $(n=10)$ and volunteers ( $n=7)$ (see Table 1$)$ and fieldnotes. Data were collected by BLINDED [first author], a female social gerontologist with 15 years of experience in the charitable ageing sector and long-standing interest in day centres, who undertook 14 once-weekly, full-day visits to each centre (same day each week); visits habituated participants to her presence and led to a trusting rapport.

Managers were asked about their centres and for background documentation. Staff and volunteer interviews covered their roles, amongst other topics.

As a qualitative but non-ethnographic study, fieldnotes made during visits aimed to inform an objective, non-evaluative account of the setting and contextualise interview data, thus were different in nature than for an observational ethnographic study reporting a researcher's interpretative perspective. They supplemented other data by recording centre operations, logistical study details (e.g. potential participants, attendance, interview plans), notable incidents, and researcher reflections.

A donation of $£ 100$ was given to each centre following fieldwork, a strategy intended to enable all attenders, carers and centre personnel to feel appreciated whether or not they were interviewed.

Fieldnotes were typed up resulting in 72 pages of notes. Interviews were audio recorded, transcribed, anonymised and entered into Nvivo (QSR, 2015) software for analysis. Data were then distilled into four individually presented case studies. BLINDED [first author] undertook analysis, supported by team meetings with BLINDED [second and third authors] in which analysis was discussed and verified. For this article, data are presented thematically, with anonymity protected. As this article aims to be non-evaluative by presenting factual details, not perspectives or interpretations, fieldnotes and interviews are not cited. The SRQR (O'Brien et al. 2014) and COREQ (Tong et al. 2007) checklists for reporting qualitative research were followed.

Table 1

Data Sources

\begin{tabular}{|c|c|c|c|c|c|}
\hline $\begin{array}{l}\text { Data sources for } \\
\text { article sections }\end{array}$ & $\begin{array}{l}\text { Field } \\
\text { notes }\end{array}$ & $\begin{array}{l}\text { Documentation } \\
\text { provided }\end{array}$ & $\begin{array}{l}\text { Manager } \\
\text { interviews }\end{array}$ & $\begin{array}{l}\text { Staff and volunteer } \\
\text { interviews }\end{array}$ & $\begin{array}{l}\text { Study planning (pre } \\
\text { data collection) }\end{array}$ \\
\hline Aims and funding models & $\mathrm{X}$ & $\mathrm{X}$ & $\mathrm{X}$ & & $\mathrm{X}$ \\
\hline Locational contexts & $\mathrm{X}$ & & & & $\mathrm{x}$ \\
\hline The day centre environment & $\mathrm{x}$ & & $\mathrm{x}$ & & \\
\hline Formal and informal care and support & $\mathrm{x}$ & & $\mathrm{x}$ & $\mathrm{x}$ & \\
\hline What is in a 'day' & $\mathrm{x}$ & & $\mathrm{x}$ & & \\
\hline Charges to attenders & & $\mathrm{x}$ & & & \\
\hline $\begin{array}{l}\text { Narrative of an observed typical day and the } \\
\text { variety of activities available }\end{array}$ & $\mathrm{x}$ & $\mathrm{X}$ & - & & \\
\hline
\end{tabular}

Involvement

Involvement was via an Advisory Group of people with experience of day centres assembled for the study, which met three times, and an Advisory Group that acts as a critical friend to BLINDED [the first two authors]' workplace. Groups were consulted about study materials and interpretation of the findings. Case study site representatives attending a workshop were also consulted about interpretation of the findings.

\section{Ethics}

Ethical approval was received from the BLINDED Research Ethics Committee (BLINDED REF. NO.) and local authority Research Governance approvals given. After receiving information about the study and having the opportunity to ask questions, interviewees gave written, informed consent to audio recording of the interviews and pseudonymised use of data gathered.

[i] Generalist day centres do not offer specialist care solely to a specific group such as people with dementia or stroke survivors.

\section{Findings}


After outlining the day centres' main characteristics, aims, model and their locality, centres' internal environments are described, and formal and informal care provided summarised. Next, operational hours, daily timings and available 'extras' are set out. Finally, charges made to attenders are then set out.

\section{Contextual aims and funding models}

Table 2 provides an overview of the case study day centres organisational and funding characteristics.

All centres aimed to improve their attenders' quality of life by focusing on their mental and physical wellbeing, mainly by making available social opportunities and a range of activities. Additionally, two aimed to offer nutritious meals and physical rehabilitation (DCLA, DCV2), two to provide information and advice (DCHA, DCLA) and one to support family carers and be a resource for the local community (DCLA). Two set their overall aims within a framework of enabling attenders to remain at home (DCLA, DCV1). Centres' differences extended to their providers, premises, operational days and hours, access arrangements, attendance numbers, funding and charges, activities, staffing, meal provision, links with the voluntary and community sector, social care and the NHS. One voluntary sector centre specified that it also aimed to work in cooperation with other agencies for the benefit of its attenders.

Table 2

Overview Organisational and Funding Characteristics of the Participating Day Centres

\begin{tabular}{|c|c|}
\hline Day Centre & Overview \\
\hline $\begin{array}{l}\text { Housing } \\
\text { Association } \\
\text { Day Centre } \\
\text { (DCHA) }\end{array}$ & $\begin{array}{l}\text { Five-day operation on ground floor of extra care housing (supported living apartments); accepted local authority referrals only; for older people with } \\
\text { eligible needs (social isolation and needing support with personal care and transport) referred by the local authority and funded by a } 10 \text {-year block } \\
\text { contract. A local authority day centre review document stated that annual running costs were } £ 304,300 \text { excluding transport (February } 2015 \text { ). Manager } \\
\text { (on secondment) reported not always having sight of the centrally-held budget. Paid frontline staff. Capacity of } 20 \text { (14 registered attenders at time of } \\
\text { research); 9-12 people were observed to attend daily during the research period. }\end{array}$ \\
\hline $\begin{array}{l}\text { Local } \\
\text { Authority } \\
\text { Day Centre } \\
\text { (DCLA) }\end{array}$ & $\begin{array}{l}\text { Five-day operation in a purpose-built centre; accepted local authority referrals and drop-ins (without assistance needs) for activities and/or lunch; for } \\
\text { older people with eligible needs. Funded by an internal budget; } 2015-16 \text { expenditure } £ 679,588 \text { excluding transport. Paid frontline staff and one part-time } \\
\text { volunteer. Capacity (with unchanged staffing levels) of approximately } 25 ; 22-28 \text { people were observed to attend. It was also open to drop-in users who } \\
\text { were self-sufficient and without eligible needs; up to } 10 \text { daily were observed to join the group for lunch. }\end{array}$ \\
\hline $\begin{array}{l}\text { Voluntary } \\
\text { Sector Day } \\
\text { Centre } 1 \\
\text { (DCV1) }\end{array}$ & $\begin{array}{l}\text { One-day operation in a church hall, provided by the local arm of a national charity; open access for people of any religion, race or ethnic origin aged } \geq 60 \\
\text { years and housebound, socially isolated who may be in receipt of care from statutory or voluntary agencies, but not for people needing lifting, personal } \\
\text { care or nursing, or people needing specialist care for mental illness; funded by a three-year Service Level Agreement (SLA) (national provider body) of } \\
£ 5,054 \text { annual maximum } 2014-2017 \text { (for } 20 \text { weekly attenders, released for actual numbers). Fundraising. Office rental cost (approx. } £ 5,000 \text { ) donated by } \\
\text { church which allowed hall use free of charge. Annual core grant from the local authority (with Service Level Agreement) for all services provided, not just } \\
\text { day centre. Frontline volunteers. Capacity of approximately } 25 ; 12-14 \text { people were observed to attend. Closes for three weeks over Christmas and the } \\
\text { New Year. }\end{array}$ \\
\hline $\begin{array}{l}\text { Voluntary } \\
\text { Sector Day } \\
\text { Centre } 2 \\
\text { (DCV2) }\end{array}$ & $\begin{array}{l}\text { Two-day operation in a multipurpose community hub, provided by a local charity affiliated to national charity; accepted both open and local authority } \\
\text { referrals; for socially isolated older people with transport needs. Not for people with personal support needs (only assistance is provided e.g. to get into } \\
\text { shower or go to toilet); funded under an annual SLA with the local authority (extended annually for the previous } 3 \text { years after its } 3 \text {-year contract ended) } \\
\text { for up to } 15 \text { per day. Income and expenditure are integrated for provider's } 3 \text { centres, with each place costing the provider approximately } £ 19 \text {. Raffle is a } \\
\text { small fundraiser. Paid staff and volunteers. Capacity of approximately } 25 \text { ( } 11 \text { registered attenders at time of research); } 6-11 \text { people were observed to } \\
\text { attend. Closed Christmas Day to 5th January. }\end{array}$ \\
\hline
\end{tabular}

\section{Locational contexts}

Few of the day centre studies reviewed provide a sense of centres' location yet, for older people accessing any services, proximity is often an important factor in what they see as accessible (Van Dijk et al., 2015). Likewise, being located in, and part of, the local community can be an important consideration in providing a sense that such a service is a community resource. Therefore, data were collected on the local environment, noting indications of being part of local communities or otherwise, visible in localities or set aside and segregated (Goffman, 1961).

DCHA was near a busy road of shops in an urban district close to former heavy industry sites and near large public housing estates, in an area being developed and increasingly gentrified. DCLA was in a residential urban area, midway between two district High Streets. Both were in poorer communities, classified as being in areas included within band of the $30 \%$ most deprived areas, according to the English Index of Multiple Deprivation[i] (IMD) (Ministry of Housing, 2015). DCV1 was in the middle of a small town in an area of socio-economic extremes with more social housing than the national average. DCV2 was close to the middle of a rural town surrounded by villages, and in area of socio-economic extremes, classified by IMD as being in the middle band of deprivation.

\section{The day centre environment}

One distinction between day hospitals and day centres lies in their ambiance and the messages it gives about the building's purpose, the role of staff and volunteers, and the people who go there. Day hospitals are sites of treatment and clinical activity with single use and purpose (Smith \& Cantley, 1985); day centres may convey a sense of socialisation and multiple usage. Some are purpose built; others adapted to new functions.

DCHA's purpose-built building was designed to have flexible usage by having an activity room and three main areas that could be separated by folding doors (which were left open): one was the television area with upholstered armchairs, coffee tables and a goldfish tank; the second a recreational area, with wooden tables and plastic-cushioned wooden chairs, equipment and games cupboards, a small pool table and a table tennis table; and the third a dining room shared with the extra care facilities' residents. The main room overlooked an accessible garden. Toilets were off the corridor to the centre; one had a ceiling hoist track. The centre had been recently decorated in bright, homely colours. At the building's entrance were two sofas, another fish tank and a leaflet stand. 
Facilities communal to the extra care building also used by the centre were a hairdressing salon, the bathroom with a hoist and a Consultation Room. Tenants were able to join attenders for lunch in the dining room, and, for a small fee, could join the group for afternoon refreshments and bingo. The building thus shared aspects of a communal age-specific building; with attempts to spatially separate different domestic activities; recreation, eating, and relaxation.

Similarly, standalone DCLA's central area was a large L-shaped room (the 'dining room'), set with groups of tables with plastic-padded wooden chairs, surrounded by recreational activities: a dedicated jigsaw table, a games table, shelves with more games, books and playing cards, a pool table, a table tennis table and a two-seater sofa. Leading off this room were an arts and crafts room (with a piano), a computer room, a conservatory, a small meeting room with a kitchenette, a television room, a quiet room with books and videos on shelves, a treatment room (housing a hair-washing sink, a bed, lockers and a massage table), a large kitchen with heated serving containers and a serving hatch to the dining room, and toilets. The room overlooked an accessible garden. Down a small corridor were a small office, a room with a bed for attenders feeling tired or unwell, and a bathroom with a toilet, an accessible bath and a changing table; both the latter had mobile hoists. Through this was a laundry. Fabric-upholstered chairs suffering continence 'accidents' were steam-cleaned by staff. At the entrance was the receptionist's and staff office.

In contrast, the long, rectangular hall where DCV1 operated adjoined the church's main worship area via a folding partition wall, making use of a community asset. With a high ceiling and windows, the room was bright and airy but not cold. There was a raised stage and a kitchen with a serving hatch. Toilets, shared with other building users, were across the lobby through the main hall entrance door. The hall was set up in the morning by a volunteer and one 'active member' (a status assigned by the centre's manager to people indicating a wish to be actively involved in providing the service). Three trestle tables were laid out at different angles for lunch and dressed with flowery vinyl tablecloths, small blue vases with artificial daisies, cutlery and flowery plastic tumblers containing a folded napkin providing an atmosphere of hospitality. On the other side, near the stage, was a semi-circle of fabric-upholstered wooden chairs with small, folding tables in front of pairs of chairs. On the stage was the day's paraphernalia (e.g. magazines). This fully accessible building also had several meeting rooms, a café (opened twice weekly), a vestry, the church office and the provider's office. Although in a shared building and in a hall with three doors, attenders did not get lost. However, at the end of the day, vigilance was key for the volunteers and managers as one attender with dementia repeatedly tried to leave before the driver was ready. Occasionally, chairs suffered continence 'accidents' and were placed aside to be cleaned by building maintenance staff.

The 'community hub' building DCV2 operated in was the site of a variety of community facilities and organisations and may be one of those buildings increasingly described as an 'anchor institution' (Jackson \& Mclnroy, 2015). Shared users included a library, a church, a housing association's offices, an Advice Bureau, a young people's organisation offering recreational activities and advice, a sensory room and a day centre for adults with learning disabilities that operated in the room used by DCV2 on its non-operational days. The hub also hosted sessional activities (e.g. blood donation sessions, health and wellbeing drop-ins run by charities, NHS Health Trainer support with healthy eating, stress, wellbeing and managing smoking and alcohol intake, and an outreach sexual health clinic), a young carers' group, an active retired group and classes (e.g. pilates, yoga, dancing, singing and children's activities). At times, local authority advisors assisted with, for example, financial and benefits advice, disability equipment information, and death registration.

DCV2's entrance led off the library, beside the centre's reception/library desk staffed by two local authority employees. It was a large, bright room overlooking the garden. Furniture was arranged by day centre staff each morning. At the far end, brightly coloured, fabric-upholstered armchairs and two two-seater sofas were arranged in a small circle (with entrance/exit gaps) with small, folding wooden tables beside them. A wall-mounted television screen was next to glass fire doors leading to the garden and car park. Nearer the entrance were sofas, the tombola and sweet shop tables, and two six-seater lunch tables. Off the room was a cloakroom, two accessible toilets (one with an adult changing table, a shower and screen), a kitchen with a hatch through to the main area, a small meeting room, a therapy room, equipment cupboards and double doors to a sensory room.

Being part of a busy building brought challenges to cohesiveness and security. People constantly came in and out to use the kitchen and fetch items from the small meeting room. A learning disability centre attender often visited to take magazines and needed guiding back to another room. During fieldwork, the manager introduced provider-branded t-shirts to improve security. In the mornings, background noise came from children using the sensory room and the baby and toddler groups in the library. An additional staff member had been employed when the centre moved to this location because of its numerous access points. Despite the accessible toilet and therapy room having two points of entry/departure, no attenders had got lost, although staff needed to keep an eye on the only attender with more advanced dementia. The provider's manager indicated the problematic nature of shared facilities, for example, some of the twoseater sofas were too low, and fabric chairs were not suited to a group with occasional continence 'accidents'.

\section{Formal and informal care and support}

Using Lunt's (2018) categorisation, there was a mix of frontline personnel in centres. DCLA had one part-time volunteer in addition to its paid staff. DCHA was fully operated by paid staff. DCV2 was managed by a paid staff member who ran the service with two paid staff and one volunteer. DCV1's manager was also the manager of the provider organisation; volunteers provided the service, supported by the manager and assistant manager.

Centres with paid staff provided more personal care (help with continence/toilet, eating); this was formally undertaken in two centres accepting only local authority referrals, but all staff roles were varied, described by one as a 50/50 care and social role. Work involved personal care; planning, running and supporting activities, playing games with attenders, organising occasional events; providing emotional support; monitoring attenders' wellbeing and health, often by chatting on arrival or during the day, and acting where necessary; making/serving refreshments; practical support; attending to logistical requirements and acting as a key worker for named attenders and maintaining paperwork.

With reference to domestic work, staff and volunteers at all centres set and cleared tables and served meals; at DCV2, they also washed up and loaded the dishwasher. Dedicated kitchen staff at DCLA and kitchen volunteers at DCV1 prepared meals (see Table 3 for further lunch details). 
Table 3

Lunch details

\begin{tabular}{|c|c|c|}
\hline $\begin{array}{l}\text { Day } \\
\text { centre }\end{array}$ & Preparation & Serving and Clearing \\
\hline DCHA & $\begin{array}{l}\text { Contracted independent caterer. Part cooked on-site (e.g. chips, vegetables) by contractor's two } \\
\text { employees; part transported from provider's kitchen in insulated crates. } \\
\text { (First } 4 \text { weeks: supplied by a meals-on-wheels provider; heated on site by supplier employee). }\end{array}$ & $\begin{array}{l}\text { Served by meal provider staff and taken to } \\
\text { attenders by frontline staff. }\end{array}$ \\
\hline DCLA & Prepared on site by 3 day centre kitchen staff & $\begin{array}{l}\text { Served by kitchen staff and taken to attenders } \\
\text { by frontline staff. }\end{array}$ \\
\hline DCV1 & Rota of volunteer cooks (manager occasionally substituted) & $\begin{array}{l}\text { Served by kitchen volunteers and taken to } \\
\text { attenders by frontline volunteers. }\end{array}$ \\
\hline DCV2 & Prepared by local hospital; collected by minibus driver in insulated crates. & $\begin{array}{l}\text { Served by manager/staff, taken to attenders by } \\
\text { staff/volunteer. }\end{array}$ \\
\hline
\end{tabular}

All staff had received a range of training (see Table 4).

\section{Table 4}

Training Undertaken by Staff (as reported in staff interviews)

Note: Data may be incomplete as not all participants referred to their training records.

\begin{tabular}{|c|c|}
\hline Type of Training & Details \\
\hline $\begin{array}{l}\text { Practical training courses relevant to } \\
\text { work (undertaken by most participants) }\end{array}$ & $\begin{array}{l}\text { Moving/handling of people (including during personal care), first aid, food hygiene, fire safety, health and safety. Some } \\
\text { courses covered use of hoists. }\end{array}$ \\
\hline Other practical training & $\begin{array}{l}\text { Medication administration/storage }(n=6) \text {, safeguarding awareness }(n=3) \text {, manual handling in emergencies }(n=1) \text {, mental } \\
\text { health first aid }(n=1) \text {, dementia and mental health awareness }(n=4) \text {, learning disability awareness }(n=1) \text {. }\end{array}$ \\
\hline Specialist training & $\begin{array}{l}\text { Infection prevention and control, nutrition and hydration, diabetic awareness, epilepsy and pressure sore/ulcer awareness. } \\
\text { Diversity and inclusion }(\mathrm{n}=2) \text {. } \\
\text { Trusted Assessor certification enabling assessment for community equipment to assist with activities of daily living ( } \mathrm{n}=1 \text { ). } \\
\text { Working relationships and information handling }(\mathrm{n}=1) \text {. } \\
\text { Dementia (one staff was the internal dementia specialist, delivering short training sessions to other staff where time } \\
\text { allowed). }\end{array}$ \\
\hline
\end{tabular}

Activities

Chair-based exercised $(n=2)$, healthy eating $(n=1)$, craft $(n=1)$ and stroke, impact of brain injury $(n=1)$.

National Vocational Qualification (NVQ) Level 3 NVQ in Health and Social Care $(n=3)$.

qualifications Level 2 NVQ part-completed $(n=1)$.

NVQ level 2 in Health and Social Care equivalent (from another country).

NVQ assessor $(n=1)$.

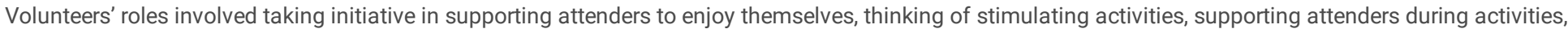

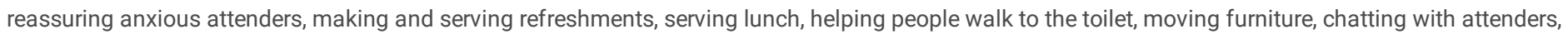

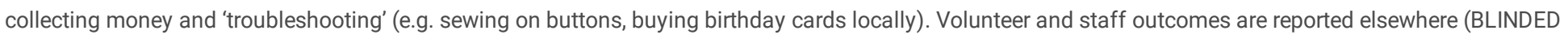

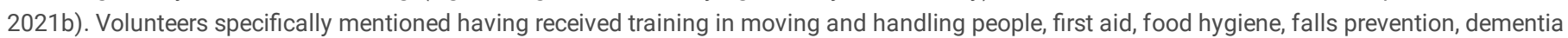
awareness, and in the Mental Capacity Act 2005.

What is in a 'day'

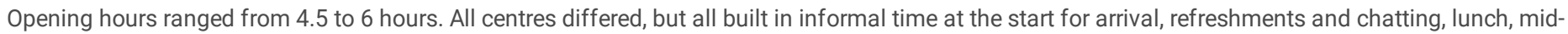

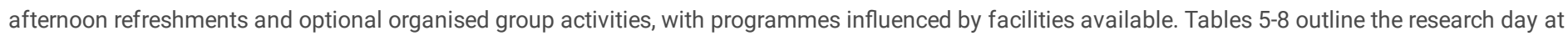

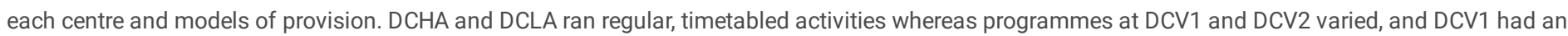

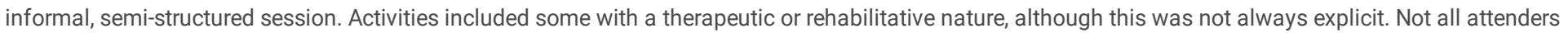

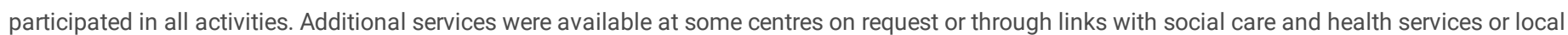

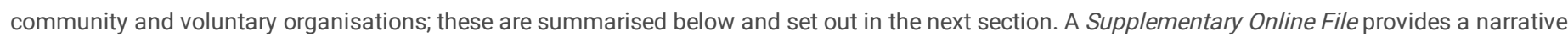
description of a 'typical day' and fuller details of the variety of activities taking place at each centre, as observed and recorded in fieldnotes.

\section{Table 5}

DCHA: The Research Day and Model As Noted During the Visit Period 


\begin{tabular}{|c|c|}
\hline DCHA & $\begin{array}{l}\text { 10:00-16:00 Operational time: } 6 \text { hours } \\
\text { (Model: Choice, activity, and socialisation) }\end{array}$ \\
\hline 10:00-10:15 & Arrival and seating in television lounge area \\
\hline 10:15-11:00 & Tea/coffee/toast in dining area \\
\hline 11:00-12:00 & Staff-led themed art/craft (activity room) or baking in the small kitchen in groups of 3 . \\
\hline $12: 00-13: 00$ & $\begin{array}{l}\text { Lunch in dining area } \\
\text { ( } 2 \text { courses: chips/mashed potato with fish/chicken/sausages; dessert options. Rota menu provided in advance, but same options every research } \\
\text { day) }\end{array}$ \\
\hline $13: 15-14: 15$ & Staff-led singalong in activity room \\
\hline $14: 15-15: 00$ & Self-directed/informal activities in recreational area (dominoes, colouring or craft) \\
\hline 15:00-15:30/45 & Tea/coffee/biscuits/baked items in dining area \\
\hline $15: 30-15: 45$ & Bingo in dining area (fortnightly) called by an attender \\
\hline 15:45-16:00 & Attenders move to television lounge and prepare to leave; transport arrived and attenders left at 16:00. \\
\hline $\begin{array}{l}\text { Available on } \\
\text { request }\end{array}$ & Nail filing and painting were available by staff (no charge). \\
\hline $\begin{array}{l}\text { Available through } \\
\text { local links }\end{array}$ & $\begin{array}{l}\text { Two clothes vendors visited regularly: one ran a 'clothes party' in the building's communal reception area; the second brought a selection of clothes } \\
\text { from her market stall and ordered colours and sizes on attenders' request. } \\
\text { Weekly podiatry; people usually attending on a different day could request an appointment (inclusive of transport). } \\
\text { District nurses visited to change dressings by individual arrangement. } \\
\text { Audiology visits arranged individually. } \\
\text { Community Mental Health Team visited to carry out assessments. }\end{array}$ \\
\hline
\end{tabular}

Table 6

DCLA: The Research Day and Model As Noted During the Visit Period

\begin{tabular}{ll}
\hline DCLA & $\begin{array}{l}\text { 09:30-14:30/10:30-15:30 Operational Time: } 5 \text { hours } \\
\text { (Model: Choice, activity, and company) }\end{array}$ \\
\hline $09: 30 \& 10.30-$ & Arrival, refreshments, toast on request (in main dining room)
\end{tabular}

11.00

11:30-12:00 Staff-led seated exercise class in arts and crafts room

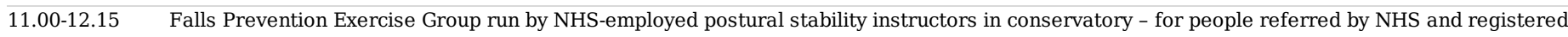
attenders

12:15-13:15 Lunch

(3 courses: soup, hot fish/meat/vegetarian option or choice of salads or baked potato, and hot dessert. Specific dietary needs catered for on request. 5-week menu rota displayed.)

13:30-14:30 Memory exercises in the meeting room with kitchenette (e.g. focused card games, reminiscence activities)

13:30-14:00 Refreshments (including biscuits) served from refreshment trolley by kitchen staff (wherever attenders are)

14:30-15:00 Healthy Eating session in the meeting room with kitchenette (varied activities e.g. quizzes and cooking)

14:30 \& 15:30 Transport arrived. Staff collected attenders from rooms, assisted them to get ready and attenders left with escorts.

Available on Blood pressure checks.

request Computer tablets.

Available Free internet/computer access at the online centre.

through local Hairdresser visited fortnightly.

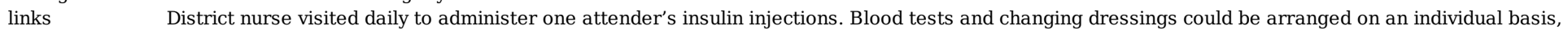
an arrangement set up by the centre's manager so that attenders did not miss their attendance days for health appointments.

Weekly Primary Care Falls Service falls prevention exercise group (by referral only).

During fieldwork:

- an optician visited to check an attender's new reading glasses were satisfactory after being unable to contact her at home.

- an NHS Rehabilitation Team visited to assess an attender who was progressing from a walker to a stick after a long hospital stay. 
Table 7

DCV1: The Research Day and Model As Noted During the Visit Period

\begin{tabular}{|c|c|}
\hline DCV1 & $\begin{array}{l}\text { 10:30-15:00 Operational Time: } 4.5 \text { hours } \\
\text { (Model: Activity and group entertainment) }\end{array}$ \\
\hline $10: 30-11: 00$ & Arrival, tea/coffee/biscuits, lunch information, sale of fundraising raffle tickets \\
\hline 11:00-12:00 & $\begin{array}{l}\text { Whole group activity } \\
\text { (e.g. 1950s reminiscence talk, exercises with a physiotherapist, arts and crafts, dance performances, singalong, musical bingo) }\end{array}$ \\
\hline $12: 00-13: 00$ & $\begin{array}{l}\text { Lunch } \\
(2 \text { courses: set menu) }\end{array}$ \\
\hline $13: 10-13: 30$ & Church service (optional extra) \\
\hline $13: 30-15: 00$ & $\begin{array}{l}\text { Informal small group activities } \\
\text { (card games, dominoes or triangular dominoes and colouring books/magazines/word-searches) }\end{array}$ \\
\hline $14: 15-14: 30$ & Refreshments at tables (including biscuits or sweets) \\
\hline $14: 30-15: 00$ & Transport arrived and attenders got ready to leave. \\
\hline Also available & $\begin{array}{l}\text { Weekly short worship service in the adjoining church. } \\
\text { Trained volunteers ran a monthly hearing aid maintenance clinic. } \\
\text { 'Message in a Bottle' kits }{ }^{[\mathrm{ii}]} \text { were given to new attenders, to be used by emergency services visiting their homes. }\end{array}$ \\
\hline
\end{tabular}

Table 8

DCV2: The Research Day and Model As Noted During the Visit Period

\begin{tabular}{|c|c|}
\hline DCV2 & $\begin{array}{l}\text { 10:00-15:00 Operational Time: } 5 \text { hours } \\
\text { (Model: Group activity - centre-based and beyond) }\end{array}$ \\
\hline 10:00-11:00 & Arrival, refreshments/toast, lunch orders, sweet shop, tombola \\
\hline 11:00-12:00 & Whole group activity (e.g. themed group or individual quizzes, charades, floor hoopla, discussion about local places). \\
\hline $12: 15-13: 15$ & $\begin{array}{l}\text { Lunch } \\
\text { ( } 2 \text { courses: } 3 \text { hot meal options, including vegetarian, or salad selections, with a choice of hot dessert, yoghurt, fruit or cheese and biscuits) }\end{array}$ \\
\hline $13: 30 / 14: 00-14: 45$ & $\begin{array}{l}\text { Whole group activity (staff- or externally-led) } \\
\text { (e.g. themed poetry reading and discussion, yoga, musical performance, musical bingo, talks, outside trips) }\end{array}$ \\
\hline
\end{tabular}

14:15-14:30 Refreshments (including biscuits or sweets)

14:45-15:00 Transport arrived and attenders were helped to get ready to leave.

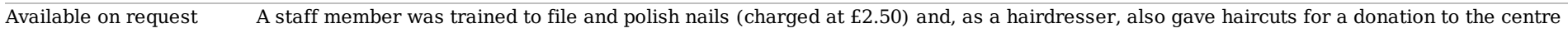
(usually £5).

Shower.

Two attenders regularly visited the library.

One used the co-located advice service after staff arranged appointments.

Available through local Self-employed chiropodist visited fortnightly, providing heavily discounted treatment.

links Optician visited twice yearly.

District nurse visits individually arranged.

More regularly, the centre hosted a local charity-operated Monthly Hearing Aid Clinic (open to local residents of the area and attenders),

Self-employed masseuse (six-weekly for attender and external bookings).

Visiting artisan who sold jewellery.

Local authority-employed Community Warden visited occasionally to check if attenders had concerns needing addressing

Provider website stated eye tests are also available on request.

Charges to attenders

Full finance details, including individual payment methods, were not made available. Centres charging systems, attendance, meal and transport charges varied (see Table 9). Voluntary sector centre charges were lower as they were subsidised by grants, contracts and fundraising.

Table 9

Charging and Payment Details 


\begin{tabular}{|c|c|c|c|c|}
\hline $\begin{array}{l}\text { Day } \\
\text { Centre }\end{array}$ & Daily Charge to Attenders & Transport & Meal / Refreshments & Payment \\
\hline$\overline{\mathrm{DCHA}}$ & $£ 38.94$ & $\begin{array}{l}\text { Organised/paid without day } \\
\text { centre involvement. }\end{array}$ & $\begin{array}{l}£ 6 \text { ( } € 3.50 \text { first } 4 \text { weeks - subsidised). } \\
\text { Refreshments } € 1 \text { (unused funds, administered by } \\
\text { attender committee, are used for extras, e.g. } \\
\text { entertainment, parties.) }\end{array}$ & $\begin{array}{l}\text { Self-funding attenders } \\
\text { invoiced in arrears by local } \\
\text { authority. } \\
\text { Refreshments payable on } \\
\text { day. }\end{array}$ \\
\hline DCLA & $\begin{array}{l}£ 25 \\
\text { 'Drop-in' clients (without assessed } \\
\text { needs): } £ 2.00 \text { for a maximum of half a } \\
\text { day’s attendance. }\end{array}$ & $\begin{array}{l}\text { Only for people with assessed } \\
\text { needs (and personal budgets). } \\
\text { Not chargeable. }\end{array}$ & $\begin{array}{l}£ 4.10 \text {. } \\
20 p \text { tea, } 25 p \text { coffee. }\end{array}$ & $\begin{array}{l}\text { Self-funding attenders } \\
\text { invoiced in arrears by local } \\
\text { authority. }\end{array}$ \\
\hline DCV1 & $£ 1$ plus annual membership fee (£24). & $£ 3.50$ & $£ 4.50$ lunch and 3 sets of tea/coffee/biscuits & $\begin{array}{l}\text { Membership payable 6- } \\
\text { monthly. } \\
\text { Subscription/lunch payable } \\
\text { on day. }\end{array}$ \\
\hline DCV2 & $£ 12$ inclusive of lunch and transport & & $35 p$ breakfast toast & $\begin{array}{l}\text { Payable on day. Monthly } \\
\text { invoices in arrears by } \\
\text { individual arrangement. }\end{array}$ \\
\hline
\end{tabular}

[i] Deprivation scores areas derived from income, employment, education/skills/training, health/disability, crime, barriers to housing and services and living environment deprivation.

[ii] A small plastic stickered container with medication and contact details for use in emergencies is stored in the fridge door and a sticker placed beside the front door' emergency services are familiar with these kits.

\section{Discussion}

We have provided contemporary and rich descriptions of four distinct English day centres for older people. Operational descriptions and narrative accounts of days provide greater depth than other accounts and highlight centres' diverse nature, thus furthering the understanding of these services and providing background for debates about day centres and their optimisation which have been newly stimulated by the Covid-19 pandemic.

We have clarified what makes 'the day centre' a multi-faceted intervention that each attender is likely to experience differently due to its complexity and heterogeneity. It incorporates door-to-door accompanied transport to a fixed venue with varying facilities, a meal, refreshments, a group of peers, trained staff/volunteers (some of whom may be older themselves; see BLINDED 2021b) who provide both care and emotional, physical and practical support, the opportunity to socialise and participate (or to witness without participating) a variety of structured or unstructured activities or be entertained, group outings, and access to other services or activities local partnership working has facilitated. Contextual data presented here support interpretation of other studies' findings, such as outcomes for day centre attenders, volunteers and carers, and the service's focus on relationships (e.g. Hagan \& Manktelow, 2021; Lunt, Shiels, et al., 2021; BLINDED 2020a, 2021a, 2021b).

The Covid-19 pandemic has demonstrated how withdrawal of structured social contact can be detrimental (Giebel et al., 2020; Tuijt et al., 2021), and spotlighted a desire for relationship-based public services (Mackenzie, 2021). Increased numbers of people sought support from other social care services due to temporary pandemic-related service closures (ADASS, 2021a). One local voluntary sector provider blogged that "admission to residential care for eight of our [day centre] service users was disappointing for staff, of concern to relatives and an added financial cost to the local authority (...) but also an ironic indication of the preventative value of day care, which is sometimes viewed as an outdated service" (Lee, 2020). Another reported re-opening its day centres as early as possible because its members said they would rather risk infection than be consistently at home (Newton, 2021).

Giebel et al.'s (2020) study of carers and people living with dementia, undertaken during the early part of the pandemic in the UK, concluded that "nothing can replace the face-to-face human social interaction and the impact this has on someone's well-being." Despite some providers maintaining contact with day centre attenders and carers via regular phone calls or internet-based activities, the latter were not always successful particularly for people with dementia living alone or with more advanced dementia (Giebel et al., 2020). Just over half of UK people aged 75 or older were recent internet users in 2020 (ONS, 2021), so attempts at digital remote support may be jeopardised. Many lack internet competence (Age UK London, 2021; Hargittai et al., 2019) and may lack a support person. Numbers of people living alone are increasing, especially among the oldest old (Kempton \& Tomlin, 2014). Many day centre attenders live alone (Lunt, 2018; BLINDED 2020a). People ageing without children, an increasing group (ONS, 2020), felt extremely isolated during the pandemic with the withdrawal of group activities (Collieson, 2021) and face additional disadvantage as much practical support is from adult offspring (Pickard et al., 2007).

At the time of writing (October 2021), the English day care sector is still not fully operational despite national guidance allowing formally organised support groups for up to 15 people since July 2020, and 30 people from May 2021. In April 2021, estimated commissioned day centre places, for all adults, had reduced to two-thirds when compared with February 2020 places (pre-pandemic) (ADASS, 2021b). Operational challenges to re-opening for the not-for-profit sector include substantial income reductions due to reduced fundraising activity, unavailable volunteers due to Covid-19 vulnerability, and difficulties ensuring a Covid-safe environment (Groundwork UK, 2020; Townsend, 2021). 
Greater need for voluntary sector services, post-pandemic, has been mooted due to increased isolation and anxiety among older people, reduced physical activity affecting health and wellbeing, and increased carer stress (Groundwork UK, 2020). With residential care reported as a less attractive option postCovid (Quilter-Pinner \& Sloggett, 2020), alternative options, such as day centres, will increase in importance, particularly given high digital exclusion among older people and because internet-based provision does not enable a change of scene or personal care, something day centre attenders value (BLINDED 2020b). Within this context, day centres' suitability to support recovery has been proposed (Green et al., 2021; Lunt, Shiels, et al., 2021).

We now briefly comment upon centres' aims, local collaborations and finances.

Contrary to Tester's (1989) finding, centres' aims were clearly defined but differed in specificity. Aims addressed English health and social care policy target areas and were consistent with recent literature (BLINDED 2020b).

This article links with the current English policy agendas of ageing in place (growing older at home with changing needs), prevention and early intervention and partnership working (HM Government, 2014), planned growth in social prescribing (NHS, 2019), and interest in the potential of community assets. Under an asset-based approach, day centres can be considered 'anchor institutions' which promote the health and wellbeing of individuals in a local community (Daly \& Westwood, 2018). Social prescribers, social care and health professionals, including those who are peripatetic or community-based (e.g. undertaking outreach or medical visits), may wish to make themselves aware of their local day centres, the services they offer and facilities available.

Exploring potential future collaborations is recommended. Most local authorities want to invest in prevention and new ways of working; these are an important way to deliver savings whilst recognising that statutory funding for local services continues to be problematic (ADASS, 2021b). Some examples of additional services or support for attenders resulting from local links have been provided here. Most had been developed by DCLA, something possibly linked with its larger size, flexible, standalone premises, five-day operation and more stable funding.

A hindrance may be "difficulties in obtaining accurate information on costs", also experienced by Tester (1989, p. 176). Day centre finances are complicated, by varied funding sources, staffing and attendance differences, building ownership, estates costs, and transactions with public sector bodies. This perhaps explains the lack of research about cost-effectiveness (Ellen et al., 2017). The present study and Lunt's (2018) were able only to report attendance charges, and even these are not often publicly available (Green et al., 2021). Apart from the Personal Social Services Research Unit's annual Unit Costs work, which covers local authority day care provision (https://www.pssru.ac.uk/project-pages/unit-costs/), only one English study has reported income streams and financial viability of 12 day centres for people with disabilities while operating as social enterprises (Powell, 2015; Powell et al., 2019). Several finance questions remain unanswered (e.g. cost per hour/day/place/transport for different models of provision).

Further exploration of finances would improve understanding of service provision within the current social care market in which funding and clientele levels fluctuate or are uncertain, and be important in the context of sustainability, reduced commissioning and a need for clarity for individual consumers. Progress would support the use of the Adult Social Care Outcomes Toolkit (ASCOT) (Netten et al., 2012), a cost-utility tool recommended for economic evaluations (Balamu et al., 2015; Makai et al., 2014). Social Return on Investment exercises would build a better understanding of day centres with a view to maximising their use and potential.

\section{Limitations and strengths}

The research was undertaken at a time of financial cuts and service reviews. Reviews, reduced numbers of centres and lack of publicly available information meant some typologies were not represented, for example, small, entirely volunteer-run day centres without national affiliations and for-profit centres (all of the latter identified specialised in dementia care).

Centres' typological and location diversity helped compensate for the study's limitations which relate to the small number of participating centres in one region and the inclusion of data from the agreed research days; other days may have differed in attender profile, activities and staffing. International comparisons are difficult as models differ between, and within, countries.

Strengths lie in the study's in-depth nature, resulting an in-depth snapshot of one day at each centre, and focus on generalist day centres. Risk of disruption to normal activity and practises was minimised by regular full-day visits which habituated attenders, volunteers and staff to the researcher and led to a trusting rapport. A risk of bias is that poor-quality day centres may not have agreed to participate.

\section{Conclusion}

This article has updated the English evidence base about older people's day centres not specialising in the care of older people with dementia by setting out the details of what happens in these services and local links in place. It shows how 'the day centre' is a multi-faceted intervention within a local context encompassing many different planned and unplanned elements. Some may be part of anchor institutions, others offer opportunities for asset-based community development, drawing on mutual aid and volunteering support.

One Covid pandemic legacy is a greater understanding of the need for in-person, face-to-face (relational) contact and the difficulties experienced by certain groups of older people when their supportive relationships delivered via day centres were halted. Given the importance of relationship based public services (Mackenzie, 2021), it may be timely to re-examine the value and broader use made of these services, and their buildings/activities, which have tended to remain invisible to scrutiny due to their smaller scale, exclusion from regulatory frameworks and patchy online presence (Green et al., 2021). Rather than focusing on these as resource-heavy services, consideration could be given to what they do, and could offer - to individuals, their staff and volunteers, the social care sector, the wider community, local authorities, the health service, and the education sector - within the context of a preventive and early intervention approach espoused by policy.

Page $11 / 19$ 


\section{Declarations}

\section{Contribution of authors}

BLINDED [first author] jointly developed the research proposal for this study, undertook the research reported in this article and wrote the manuscript. BLINDED [second and third authors] supervised the project. BLINDED [second author] was involved in developing the research proposal and contributed to the content and editing of the manuscript. BLINDED [third author] commented on drafts of this article.

\section{Transparency statement}

The lead author affirms that this manuscript is an honest, accurate, and transparent account of the study being reported; that no important aspects of the study have been omitted.

\section{Acknowledgements}

The authors extend thanks to study participants (and non-participants with whom the first author spent time at the centres), day centre provider organisations for agreeing to be involved, initial local authority contacts and members of the Study Advisory Group and the BLINDED's Service User and Carer Advisory Group for their contributions.

\section{Conflicts of interests}

The authors declare that there is no conflict of interest.

\section{Funding}

This work was supported by BLINDED [BLINDED REF NO. BLINDED [first and second authors] are supported by the BLINDED. The views expressed are those of the authors and not necessarily those of the funders. Funders had no input to the study design, recruitment, data collection, analysis or interpretation, or in writing this paper.

Ethics: Ethical approval was received from the Health Research Authority's Social Care Research Ethics Committee (ref: 15/IEC08/033) and local authority Research Governance approvals given. Before taking part, having been provided with an Information Sheet and the opportunity to ask questions, all participants gave informed consent to audio recording of the interviews and pseudonymised use of the data.

\section{References}

ADASS. (2021a). ADASS Activity Survey 2021.Association of Directors of Adult Social Services. https://www.adass.org.uk/media/8714/adass-activity-survey2021-cpdf.pdf

ADASS. (2021b). ADASS Spring Survey.Association of Directors of Adult Social Services. https://www.adass.org.uk/media/8762/adass-spring-survey-report2021.pdf

Age UK London. (2021). Mind the digital gap: older Londoners and internet use during the pandemic.Age UK London. https://www.ageuk.org.uk/bpassets/globalassets/london/documents/campaigns/mind-the-digital-gap-report.pdf

Allen, K., \& Miller, R. (2013). Prevention services, social care and older people: much discussed but little researched? Research findings. (Support for people with complex needs: findings). National Institute for Health Research. School for Social Care Research.

http://blogs.Ise.ac.uk/socialcareevidenceinpractice/files/2013/02/Findings_17_prevention-initiatives_web.pdf

Balamu, N. B., Kaambwa, B., \& Ratcliffe, J. (2015, 2015/11/09). A systematic review of instruments for measuring outcomes in economic evaluation within aged care. Health and Quality of Life Outcomes, 13(1), 179. https://doi.org/10.1186/s12955-015-0372-8 
Boen, H., Dalgard, O. S., Johansen, R., \& Nord, E. (2010). Socio-demographic, psychosocial and health characteristics of Norwegian senior centre users: a crosssectional study. Scandinavian Journal of Public Health, 38(5), 508-517. https://doi.org/10.1177/1403494810370230

Collieson, J. (2021). A lonely place to be.Ageing Well Without Children.

Creswell, J. (2013). Qualitative Inquiry and Research Design. Choosing Among Five Approaches (3rd ed.). Sage Publications.

Daly, M., \& Westwood, S. (2018). Asset-based approaches, older people and social care: an analysis and critique. Ageing and Society, 38(6), 1087-1099. https://doi.org/10.1017/S0144686X17000071

Ellen, M. E., Demaio, P., Lange, A., \& Wilson, M. G. (2017, Nov 10). Adult Day Center Programs and Their Associated Outcomes on Clients, Caregivers, and the Health System: A Scoping Review. Gerontologist, 57(6), e85-e94. https://doi.org/10.1093/geront/gnw165

Fields, N. L., Anderson, K. A., \& Dabelko-Schoeny, H. (2014). The Effectiveness of Adult Day Services for Older Adults: A Review of the Literature From 2000 to 2011. The Journal of Applied Gerontology, 33(2), 130-163. https://doi.org/http://dx.doi.org/10.1177/0733464812443308

Finnanger-Garshol, B., Pedersen, I., Patil, G., Eriksen, S., \& Ellingsen-Dalskau, L. H. (2021). Emotional well-being in people with dementia - A comparative study of farm-based and regular day care services in Norway. Health \& Social Care in the Community, 00(n/a), 1-12.

https://doi.org/https://doi.org/10.1111/hsc.13601

Fixsen, A., Seers, H., Polley, M., \& Robins, J. (2020, 2020/06/24). Applying critical systems thinking to social prescribing: a relational model of stakeholder "buy-in". BMC Health Services Research, 20(1), 580. https://doi.org/10.1186/s12913-020-05443-8

Flyvbjerg, B. (2016, April 1, 2006). Five Misunderstandings About Case-Study Research. Qualitative Inquiry, 12(2), $219-245$.

https://doi.org/10.1177/1077800405284363

Giebel, C., Cannon, J., Hanna, K., Butchard, S., Eley, R., Gaughan, A., Komuravelli, A., Shenton, J., Callaghan, S., Tetlow, H., Limbert, S., Whittington, R., Rogers, C., Rajagopal, M., Ward, K., Shaw, L., Corcoran, R., Bennett, K., \& Gabbay, M. (2020). Impact of COVID-19 related social support service closures on people with dementia and unpaid carers: a qualitative study. Aging \& Mental Health, 1-8. https://doi.org/10.1080/13607863.2020.1822292

Goffman, E. (1961). Asylums: Essays on the Social Situation of Mental Patients and Other Inmates. Anchor Books.

Green, C. (2018, 11 Aug). Sheer scale of council cuts to day centres is forcing families to put loved ones in full-time care. The Telegraph. www.telegraph.co.uk/news/2018/08/11/sheer-scale-council-cuts-day-centres-forcing-families-put-loved/

Green, C., Orellana, K., Manthorpe, J., \& Samsi, K. (2021). Caring in company: a pre-Covid snapshot of day centres in south London. Report of a mapping exercise of publicly available information from four south London boroughs. King's College London \& NIHR ARC South London. https://kclpure.kcl.ac.uk/portal/en/publications/caring-in-company-a-precovid-snapshot-of-day-centres-in-south-london(1d428384-55a6-4cb4-92b3d78632982274).html 
Groundwork UK. (2020). Community groups in a crisis: insights from the first six months of the Covid-19 pandemic. Groundwork UK. https://www.groundwork.org.uk/wp-content/uploads/2020/11/Groundwork-report-Community-groups-and-Covid-19.pdf

Gubrium, J. F. (1986). Oldtimers and Alzheimer's: The Descriptive Organization of Senility. JAI Press. https://doi.org/10.1177/089124167800700102

Hagan, R. J., \& Manktelow, R. (2021). 'I shall miss the company': participants' reflections on time-limited day centre programming. Ageing and Society, 41(12), 2933-2952. https://doi.org/10.1017/s0144686x20000689

Hargittai, E., Piper, A. M., \& Morris, M. R. (2019, 2019/11/01). From internet access to internet skills: digital inequality among older adults. Universal Access in the Information Society, 18(4), 881-890. https://doi.org/10.1007/s10209-018-0617-5

Hasson, F., Jordan, J., McKibben, L., Graham-Wisener, L., Finucane, A., Armour, K., Zafar, S., Hewison, A., Brazil, K., \& Kernohan, W. G. (2021). Challenges for palliative care day services: a focus group study. BMC Palliative Care, 20(1), 11. https://doi.org/10.1186/s12904-020-00699-7

Hazan, H. (1980). The limbo people. A study of the constitution of the time universe among the aged. Routledge and Kegan Paul.

HM Government (2014). Care Act 2014. www.legislation.gov.uk/ukpga/2014/23/contents/enacted

Hostetler, A. J. (2011). Senior centers in the era of the "Third Age:" Country clubs, community centers, or something else?. Journal of Aging Studies, 25(2), 166176. https://doi.org/10.1016/j.jaging.2010.08.021

Hyett, N., Kenny, A., \& Dickson-Swift, V. (2014, May). Methodology or method? A critical review of qualitative case study reports. International Journal of Qualitative Studies on Health and Well-being, 9, 23606. https://doi.org/10.3402/qhw.v9.23606

lecovich, E., \& Biderman, A. Y. A. (2012). Quality of life among disabled older adults without cognitive impairment and its relation to attendance in day care centres. Ageing and Society, 33(4), 627-643. https://doi.org/10.1017/s0144686x12000104

Ismail, S., Thorlby, R., \& Holder, H. (2014). Focus On: Social care for older people: reductions in adult social services for older people in England]. QualityWatch, Health Foundation \& Nuffield Trust. https://www.health.org.uk/publications/qualitywatch-focus-on-social-care-for-older-people, https://www.nuffieldtrust.org.uk/files/2018-10/qualitywatch-social-care-older-people.pdf

Jackson, M., \& McInroy, N. (2015). Creating a Good Local Economy: The Role of Anchor Institutions. Centre for Local Economic Strategies. www.cles.org.uk/publications/creating-a-good-local-economy-the-role-of-anchor-institutions

Kempton, J., \& Tomlin, S. (2014). Ageing alone: Loneliness and the 'Oldest Old'. Centre Forum.

Kuzuya, M., Masuda, Y., Hirakawa, Y., Iwata, M., Enoki, H., Hasegawa, J., \& Iguchi, A. (2006, Sep). Day care service use is associated with lower mortality in community-dwelling frail older people . Journal of the American Geriatrics Soc, 54(9), 1364-1371. https://doi.org/10.1111/j.1532-5415.2006.00860.x

Lee, Y. (2020, 21 Apr). NHS Reset: Providing a vital lifeline at a time of crisis NHS Reset. https://www.nhsconfed.org/blog/2020/07/providing-a-vital-lifeline-ata-time-of-crisis (page withdrawn at 29-7-21) 
Leong, O. S., Ghazali, S., Hussin, E. O. D., Lam, S. K., Japar, S., Geok, S. K., \& Azmi, I. S. M. (2020). Depression among older adults in Malaysian daycare centres. British Journal of Community Nursing, 25(2), 84-90. https://doi.org/10.12968/bjcn.2020.25.2.84

Liao, H. W., \& DeLiema, M. (2021, Nov). Reimagining Senior Centers for Purposeful Aging: Perspectives of Diverse Older Adults. Journal of Applied Gerontology, 4O(11), 1502-1510. https://doi.org/10.1177/0733464821996109

Liou, C. L., \& Jarrott, S. (2018). In Their Voices: Client and Staff Perceptions of the Physical and Social Environments of Adult Day Services Centers in Taiwan. Current Gerontology and Geriatrics Research, 2018, 5130472, Article 5130472. https://doi.org/10.1155/2018/5130472

Liou, C. L., \& Jarrott, S. E. (2013). Dementia and dementia care in Asia-Taiwanese experiences: elders with dementia in two different adult day service (ADS) environments. Aging \& Mental Health, 17(8), 942-951. https://doi.org/10.1080/13607863.2013.788998

Local Government Association. (2015). Commissioning for better outcomes: a route map.Local Government Association. www.adass.org.uk/policydocuments-commissioning-for-better-outcomes

Lund, A., \& Englesrud, G. (2008). 'I am not that old': inter-personal experiences of thriving and threats at a senior centre. Ageing and Society, 28(5), 675-692. https://doi.org/https://doi.org/10.1017/S0144686X07006988

Lunt, C., Dowrick, C., \& Lloyd-Williams, M. (2018). The role of day care in supporting older people living with long-term conditions. Current Opinion in Supportive and Palliative Care, 12(4), 510-515. https://doi.org/10.1097/spc.0000000000000391

Lunt, C., Dowrick, C., \& Lloyd-Williams, M. (2021, Sep). What is the impact of day care on older people with long-term conditions: A systematic review. Health \& Social Care in the Community, 29(5), 1201-1221. https://doi.org/10.1111/hsc.13245

Lunt, C., Shiels, C., Dowrick, C., \& Lloyd-Williams, M. (2021). Outcomes for older people with long-term conditions attending day care services delivered by paid staff or volunteers: a comparative study. Palliative Care and Social Practice, 15, 26323524211030283. https://doi.org/10.1177/26323524211030283

Lunt, C. A. (2018). The Impact of Day Care Services on Older People with Long Term Conditions. An Exploratory Mixed Methods Study. [Phd, University of Liverpool]. https://livrepository.liverpool.ac.uk/3025902/1/200631878_February2018.pdf

Mackenzie, P. (2021). The Social State: From Transactional to Relational Public Services.Demos. https://demos.co.uk/project/the-social-state-fromtransactional-to-relational-public-services/?mc_cid=afb75b64b0\&mc_eid=8f31648481

Makai, P., Brouwer, W. B., Koopmanschap, M. A., Stolk, E. A., \& Nieboer, A. P. (2014, Feb). Quality of life instruments for economic evaluations in health and social care for older people: a systematic review. Social Science \& Medicine, 102, 83-93. https://doi.org/10.1016/j.socscimed.2013.11.050

Manthorpe, J., \& Moriarty, J. (2013). Opportunity Knocks: Exploring the Links Between Day Opportunities and Equal Opportunities. Practice: Social Work in Action, 25(5), 317-333. https://doi.org/http://dx.doi.org/10.1080/09503153.2013.860093

Manthorpe, J., \& Moriarty, J. (2014, Jul). Examining day centre provision for older people in the UK using the Equality Act 2010: findings of a scoping review. Health \& Social Care in the Community, 22(4), 352-360. https://doi.org/http://dx.doi.org/10.1111/hsc.12065

Page 15/19 
Ministry of Housing, C. L. G. 2015. English indices of deprivation 2015, Available online at www.gov.uk/government/statistics/english-indices-of-deprivation2015 [Accessed 15 Apr 2021].

Naruse, T., Kitano, A., Matsumoto, H., \& Nagata, S. (2020). A Logic Model for Evaluation and Planning in an Adult Day Care for Disabled Japanese Old People. International Journal of Environmental Research and Public Health, 17(6), 2061. https://www.mdpi.com/1660-4601/17/6/2061

Naruse, T., Tuckett, A. G., Matsumoto, H., \& Yamamoto-Mitani, N. (2020). Measurement Development for Japanese Clients' Experiences during Adult Day Care Service Use (The J-AdaCa Tool). Healthcare, 8(4), 363. https://www.mdpi.com/2227-9032/8/4/363

Needham, C. (2011). Personalising public services: Understanding the personalisation narrative. The Policy Press.

Netten, A., Burge, P., Malley, J., Potoglou, D., Towers, A., Brazier, J., Flynn, T., Forder, J., \& Wall, B. (2012). Outcomes of Social Care for Adults: Developing a Preference-Weighted Measure. Health Technology Assessment, 16(16), 1-165. https://doi.org/10.3310/hta16160

Newton, C. 2 Jul 2021. RE: Personal correspondence. Email to K. Orellana.

NHS. (2019). The NHS Long Term Plan. NHS UK. Available online at www.longtermplan.nhs.uk.

NHS England 2020. Social prescribing and community-based support. Summary guide (Updated: June 2020). https://socialprescribinglondon.uk/wpcontent/uploads/2020/12/social-prescribing-summary-guide-updated-june-20.pdf

NHS England, Care Quality Commission, Health Education England, Monitor, Public Health England, \& Trust Development Authority. (2014). Five year forward view.NHS England. Available online at www.england.nhs.uk/five-year-forward-view [accessed 15 Apr 2018]. www.england.nhs.uk/five-year-forward-view

O'Brien, B. C., Harris, I. B., Beckman, T. J., Reed, D. A., \& Cook, D. A. (2014). Standards for reporting qualitative research: a synthesis of recommendations. Academic Medicine, 89(9), 1245-1251. https://doi.org/10.1097/ACM.0000000000000388

O' Shea, E., O' Shea, E., Timmons, S., \& Irving, K. (2019). The perspectives of people with dementia on day and respite services: a qualitative interview study. Ageing and Society, 1-23. https://doi.org/10.1017/S0144686X1900062X

ONS 2020. Childbearing for women born in different years, England and Wales

2019. https://www.ons.gov.uk/peoplepopulationandcommunity/birthsdeathsandmarriages/conceptionandfertilityrates/bulletins/childbearingforwomenbornin

ONS 2021. Statistical bulletin: Internet users in the UK:

2020. https://www.ons.gov.uk/businessindustryandtrade/itandinternetindustry/bulletins/internetusers/2020, Office for National Statistics.

Orellana, K. (2018). The role and purpose of generalist day centres for older people: Case studies of four day centres from multiple perspectives. [PhD, King's College London]. https://kclpure.kcl.ac.uk/portal/en/theses/the-role-and-purpose-of-generalist-day-centres-for-older-people(5e116108-5792-40e4-b335-

1820072abc46).html 
Orellana, K., Manthorpe, J., \& Tinker, A. (2020a). Day centres for older people - attender characteristics, access routes and outcomes of regular attendance: findings of exploratory mixed methods case study research. BMC Geriatrics, 20, 158. https://doi.org/10.1186/s12877-020-01529-4

Orellana, K., Manthorpe, J., \& Tinker, A. (2020b). Day centres for older people: a systematically conducted scoping review of literature about their benefits, purposes and how they are perceived. Ageing \& Society, 4O(1), 73-104. https://doi.org/10.1017/s0144686x18000843

Orellana, K., Manthorpe, J., \& Tinker, A. (2021a). Choice, control and person-centredness in day centres for older people. Journal of Social Work, 21(6), 13151338. https://doi.org/10.1177/1468017320952255 (First published 30 Aug 2020)

Orellana, K., Manthorpe, J., \& Tinker, A. (2021b). Making My Day. Volunteering or Working at a Day Centre for Older People: Findings of Exploratory Research in English Day Centres. Journal of Long-term Care(58), 177-191. https://doi.org/http://doi.org/10.31389/jltc.58

Pickard, L., Wittenberg, R., Comas-Herrara, A., \& King, D. (2007). Care by spouses, care by children: projections of informal care for older people in England to 2013. Social Policy \& Society, 6(3), 353-366. https://doi.org/10.1017/S1474746407003685

Polley, M., Whitehouse, J., Elnaschie, S., \& Fixsen, A. (2019). What does successful social prescribing look like? Mapping meaningful outcomes. University of Westminster.

Powell, M. (2015). Social Enterprise in Adult Day Care: Marketing and Sustainability [PhD, University of York]. https://etheses.whiterose.ac.uk/10596/1/madeline\%20powell\%20to\%20be\%20printed.pdf

Powell, M., Gillett, A., \& Doherty, B. (2019, 2019/02/01). Sustainability in social enterprise: hybrid organizing in public services. Public Management Review, 21(2), 159-186. https://doi.org/10.1080/14719037.2018.1438504

QSR. (2015). NVivo Qualitative Data Analysis Software (Version 11). QSR International Pty Ltd, https://www.qsrinternational.com/nvivo-qualitative-dataanalysis-software/home.

Quilter-Pinner, H., \& Sloggett, R. (2020, 12 Aug). Care after Coronavirus: An emerging consensus. Blog. https://www.ippr.org/blog/ippr-policy-exchange-socialcare-polling

Reddington, T., \& Fitzsimons, J. (2013). People with learning disabilities and microenterprise. Tizard Learning Disability Review, 18(3), $124-131$. https://doi.org/10.1108/TLDR-02-2013-0013

Roberton, J. (2018, 25 Sept). Government accused of fuelling loneliness crisis as day centres disappear. ITV News. http://www.itv.com/news/2018-0925/government-accused-of-fuelling-loneliness-crisis-as-day-centres-disappear/ [Accessed 6 Oct 2021]

Rokstad, A. M. M., McCabe, L., Robertson, J. M., Strandenæs, M. G., Tretteteig, S., \& Vatne, S. (2019). Day Care for People with Dementia: A Qualitative Study Comparing Experiences from Norway and Scotland. Dementia, 18(4), 1393-1409. https://doi.org/10.1177/1471301217712796

Ruddin, L. P. (2016, August 1, 2006). You Can Generalize Stupid! Social Scientists, Bent Flyvbjerg, and Case Study Methodology. Qualitative Inquiry, 12(4), 797812. https://doi.org/10.1177/1077800406288622 
Ruggiano, N., Brown, E., \& Fortuna, K. L. (2018). Adult Day Service Providers: Untapped Potential for Care Coordination. Nursing \& Health Sciences Research Journal, 1(1), 46-52.

Salari, S., Brown, B. B., \& Eaton, J. (2006, Sep). Conflicts, friendship cliques and territorial displays in senior center environments [ABOUT] [Article]. Journal of Aging Studies, 20(3), 237-252. https://doi.org/10.1016/j.jaging.2005.09.004

Smith, H., \& Cantley, C. (1985). Assessing Health Care: a study in organisational evaluation. Open University Press.

Stake, R. E. (1995). The art of case study research. Sage.

Tester, S. (1989). Caring by Day: A Study of Day Care Services for Older People. Centre for Policy on Ageing.

Thane, P. 2009. History of Social Care in England: invited evidence to House of Commons Health Select Committee. HC 1-21. The Stationery Office.

Thompson, K. H., \& Fletcher, P. C. (2019, Jan/Feb). Examining the Perceived Effects of an Adult Day Program for Individuals With Dementia and Their Caregivers: A Qualitative Investigation. Clinical Nurse Specialist, 33(1), 33-42. https://doi.org/10.1097/nur.0000000000000418

Tong, A., Sainsbury, P., \& Craig, J. (2007). Consolidated criteria for reporting qualitative research (COREQ): a 32-item checklist for interviews and focus groups. International journal for quality in health care : journal of the International Society for Quality in Health Care, 19(6), 349-

357. https://doi.org/10.1093/intqhc/mzm042

Townsend, J. (2021, 18th February 2021). Keeping company with an uninvited guest: Reinstating a daycare service during Covid-19 Day Centre Research Forum, Online. https://www.kcl.ac.uk/scwru/res/arc-sl/dcrf/2021/2021-02-18-dcrf-a-jayne-townsend-keeping-company-with-an-uninvited-guest.pdf

Tucker, S., Hughes, J., Challis, D., \& Burns, A. (2005). Services for Older People with Mental Health Problems: The Balance of Care in Cumbria (Discussion Paper M1006).Personal Social Services Research Unit (PSSRU).

http://www.nursing.manchester.ac.uk/pssru/research/servicearrangementsandintegration/cumbriabalanceofcare/cumbriapdffullversion.pdf

Tuijt, R., Frost, R., Wilcock, J., Robinson, L., Manthorpe, J., Rait, G., \& Walters, K. (2021, 2021/05/10). Life under lockdown and social restrictions - the experiences of people living with dementia and their carers during the COVID-19 pandemic in England. BMC Geriatrics, $21(1), 301$.

https://doi.org/10.1186/s12877-021-02257-z

Van Dijk, H. M., Cramm, J. M., Van Exel, J. O. B., \& Nieboer, A. P. (2015). The ideal neighbourhood for ageing in place as perceived by frail and non-frail community-dwelling older people. Ageing and Society, 35(8), 1771-1795. https://doi.org/10.1017/S0144686X14000622

Wittich, W., Murphy, C., \& Mulrooney, D. (2014, September 1, 2014). An adapted adult day centre for older adults with sensory impairment [ABOUT]. British Journal of Visual Impairment, 32(3), 249-262. https://doi.org/10.1177/0264619614540162

Wye, L., Brangan, E., Cameron, A., Gabbay, J., Klein, J. H., \& Pope, C. (2015, Sep 29). Evidence based policy making and the 'art' of commissioning - how English healthcare commissioners access and use information and academic research in 'real life' decision-making: an empirical qualitative study [journal article].

BMC Health Services Research, 15(1), 430. https://doi.org/10.1186/s12913-015-1091-x 
Yin, R. K. (2014). Case Study Research: Design and Methods. (Fifth ed.). Sage Publications.

\section{Supplementary Files}

This is a list of supplementary files associated with this preprint. Click to download.

- SupplementaryonlineNarrativeofanobservedtypicaldayvarietyofactivitiesFINAL161221.docx 